\title{
Pemodelan UML Sistem Informasi Geografis Pasar Tradisional Kota Pekanbaru
}

\author{
Sutejo \\ Program Studi Teknik Informatika Fakultas Ilmu Komputer Universitas Lancang Kuning \\ Jl. Yos Sudarso KM. 8 Rumbai, Pekanbaru, Riau, telp. 08117532015 \\ e-mail:sutejo@dr.com
}

\begin{abstract}
Abstrak
Dunia sistem informasi terdapat banyak model sistem informasi, kaitan pasar dengan sistem informasi geografis adalah untuk memberikan berbagai macam informasi, terutama letak geografis pasar tersebut. Pentingnya informasi ini memberi banyak inspirasi terhadap pembuat model untuk merancang sistem-sistem yang mendekati dunia nyata. Model sistem informasi juga diharapkan dapat digunakan sebagai alat prediksi kejadian di masa depan dengan mendasarkan pada data yang ada pada masa lalu dan masa sekarang. Sistem Informasi Geografis (SIG) ini di rancang untuk mengumpulkan data, meyimpan dan mengubah data, serta menganalisis objek beserta data geografis yang bersifat penting untuk di analisis. GIS yang disajikan dengan berbasis web pada perancangan ini juga dapat digunakan sebagai alat pemberian informasi kepada masyarakat luas. Hasil penelitian dengan pemodelan UML (Unified Modelling Language) sangat membantu dalam proses perancangan sebuah sistem informasi geografis pasar tradisional serta aplikasi sistem informasi geografis pasar tradisional berbasis web ini dapat digunakan sebagai sarana informasi pasar, khususnya bagi para calon pedagang yang ingin berdagang di salah satu pasar tradisional yang ada di Kota Pekanbaru.
\end{abstract}

Kata Kunci : Sistem Informasi Geografis, Web, Pasar Tradisional, Pemodelan, UML.

\begin{abstract}
The world of information systems provides many models of information systems, the link of market with a geographic information system is to provide various kinds of information, specially the geographical markets. The importance of this information gives a lot of inspiration for the model makers to design systems that approximates the real world. Model of information system is also expected to be used as predictors of future events by basing on the existing data on past and present. Geographic Information Systems (GIS) is designed to collect data, store and modify data, and analyzing object along with geographic data which is important for analysis. GIS is presented with a web based on this design can also be used as a tool to provide information to the general public. The results of research by modeling UML (Unified Modeling Language) is very helpful in the process of designing a geographic information system of traditional markets as well as the application of geographic information system web-based traditional market can be used as a means of market information, especially for potential traders who want to trade in one of the traditional markets in the city of Pekanbaru.
\end{abstract}

Keywords: Geographic Information Systems, Web, Traditional Market, Modeling, UML.

\section{Pendahuluan}

Pemodelan adalah penggambaran sistem nyata menjadi sebuah model yang berupa perilaku, bentuk fisik dan karakteristik lain yag mirip dengan sistem riel. Pemodelan merupakan proses pokok dalam pembuatan simulasi. Model yang baik adalah model yang efisien dan dapat diterapkan dalam program komputer. Model mungkin tidak harus detail, bisa hanya berisi 
perilaku pokok dari sistem, aspek lain yang tidak berpengaruh terhadap tujuan simulasi tidak perlu dimasukkan karena akan megaburkan perilaku sistem $\left[{ }^{1}\right]$.

Menurut Braun, et. al. 2001 Unified Modelling Language (UML) adalah suatu alat untuk memvisualisasikan dan mendokumentasikan hasil analisa dan desain yang berisi sintak dalam memodelkan sistem secara visual. Juga merupakan satu kumpulan konvensi pemodelan yang digunakan untuk menentukan atau menggambarkan sebuah sistem software yang terkait dengan objek $\left[{ }^{2}\right]$.

Unified Modelling Language (UML) adalah bahasa pemodelan untuk sistem atau perangkat lunak yang berparadigma berorientasi objek. Abstraksi konsep dasar UML terdiri dari structural classification, dynamic behavior, dan model management dapat kita pahami main concepts sebagai term yang akan muncul pada saat membuat diagram dan view adalah kategori dari diagram tersebut. UML mendefinisikan diagram-diagram sebagai Use case diagram, Class diagram, Statechart diagram, Activity diagram,Sequence diagram, Collaboration diagram, Component diagram, dan Deployment diagram $\left.{ }^{3}\right]$.

Sistem Informasi Geografis merupakan kumpulan yang terorganisir dari perangkat keras komputer, perangkat lunak, data geografi dan personil yang dirancang secara efisien untuk memperoleh, menyimpan, meng-update, memanipulasi, menganalisis dan menampilkan semua bentuk informasi yang bereferensi geografi $\left[{ }^{4}\right]$.

Sistem Informasi Geografis (SIG) adalah sebuah sistem yang didesain untuk menangkap, menyimpan, memanipulasi, menganalisa, mengatur dan menampilkan seluruh jenis data geografis $\left[^{5}\right]$. Perangkat lunak Sistem Informasi Geografis (SIG) atau Geographic Information Systems (GIS) telah berkembang pesat. Saat ini telah dikenal istilah-istilah Desktop GIS, WebGIS, dan Database Spasial yang merupakan wujud perkembangan teknologi Sistem Informasi Geografis, untuk mengakomodasi kebutuhan penyelesaian atas berbagai masalah yang hanya bisa diselesaikan melalui tekhnologi GIS ini. Melalui kemampuan SIG dalam hal memetakan letak kumpulan benda (features).

Perkembangan Sistem Informasi Geografis merupakan suatu kemajuan dibidang keilmuan dan teknologi di Indonesia. Karena itu banyak perusahaan atau instansi pemerintahan yang membutuhkan sistem informasi geografis sebagai salah satu data olahan yang sangat penting untuk dijadikan bahan analisis untuk membuat suatu perencanaan pengembangan perusahaan atau instansi Dinas pasar.

Sama dengan bangsa lain, indonesia telah lama mengenal pasar khususnya pasar tradisional. berdasarkan kamus umum bahasa indonesia, pasar berarti tempat orang berjual beli sedangkan tradisional dimaknai sikap dan cara berfikir serta bertindak yang selalu berpegang kepada norma dan adat kebiasaan yang ada secara turun temurun. Berdasarkan arti diatas, maka pasar tradisional adalah tempat orang berjual beli yang belangsung di suatu tempat berdasarkan kebiasaan $\left[{ }^{6}\right]$.Pasar Tradisional adalah pasar yang dibangun dan dikelola oleh Pemerintah, Swasta, Koperasi atau swadaya masyarakat sebagai sarana atau tempat usaha berupa, toko, kios, los tenda, koperasi, dengan modal kecil dan usaha skala kecil, didalamnya terjadi proses jual beli melalui tawar menawar. Perekonomian kota Pekanbaru memiliki peranan penting dalam bidang industri dan perdagangan dengan demikian peningkatan atau perbaikan fasilitas sarana dan prasarana harus terus dilakukan karena memiliki peranan yang cukup penting yaitu sebagai penunjang perekonomian di bidang industri dan perdagang. Di kota Pekanbaru terdapat beberapa pasar tradisional.

Pasar - pasar tersebut banyak tersebar di beberapa kecamatan di kota Pekanbaru. Karena banyaknya pasar yang tersebar di wilayah kecamatan yang ada di kota Pekanbaru maka dinas pasar khususnya dan masyarakat umumnya mengalami kesulitan dalam mendapatkan secara pasti informasi tentang lokasi dan fasilitas - fasilitas yang ada di pasar seperti jumlah kios, alamat pasar dan jarak antar pasar. Bahwa Informasi tentang lokasi dan fasilitas tersebut selama ini didapatkan masih menggunakan manual yaitu dengan data - data yang dibukukan dalam bentuk tulisan yang ada di dinas pasar. 
Beberapa penelitian terkait dengan topik penelitian pernah dilakukan $\left[{ }^{4}\right]$ dengan aplikasi Sistem Informasi Geografis untuk pemetaan lokasi Pasar Tradisional dan pasar Modern (Pusat Perbelanjaan) di Kota Solo berbasis web, sebagai sarana informasi pasar, khususnya bagi pengunjung yang ingin mengetahui tentang lokasi pasar tradisional dan pasar modern di kota Solo serta aplikasinya juga menyediakan fitur pemesanan kios bagi pengunjung yang ingin mempunyai kios. Penelitian yang dilakukan oleh $\left[{ }^{7}\right]$ dengan representasi informasi pemetaan lokasi atau posisi pasar tradisional di Kota Denpasar berdasarkan kebutuhan fungsional yang telah ditetapkan dengan menggunakan framework YII. Pengembangan sistem yang dilakukan menggunakan kaidah pendekatan konvensional atau terstruktur dalam pengembangan perangkat lunak yaitu membuat perancangan sistem menggunakan Data Flow Diagram (DFD) yang terdiri atas konteks diagram dan level 1.

Berdasarkan latar belakang dan penelitian-penelitian terkait sebelumnya maka dalam penelitian ini akan dilakukan Pemodelan UML Sistem Informasi Georafis Pasar Tradisional di Kota Pekanbaru. Metode pengembangan sistem yang digunakan pada penelitian ini menggunakan konsep permodelan Object Oriented karena konsep ini menganalogikan sistem seperti kehidupan nyata yang didominasi oleh obyek dan digambarkan atau dinotasikan dalam simbol-simbol yang cukup spesifik. Sejalan dengan meningkatnya perekonomian dalam hal perdagangan maka pihak dinas pasar kota Pekanbaru perlu membuat peta persebaran pasar dalam bentuk pogram aplikasi yang dapat diakses khususnya oleh dinas pasar dan umumnya masyarakat agar dengan mudah lokasi pasar tersebut dapat diketahui.

\section{Metode Penelitian}

Sebelum merancang sistem, terlebih dahulu dilakukan beberapa tahapan awal, selanjutnya akan diuraikan kerangka kerja penelitian berdasarkan gambar 1 di bawah ini, yaitu:

\begin{tabular}{|c|c|c|c|}
\hline Tahapan & \multicolumn{2}{|c|}{ Tindakan } & $\begin{array}{c}\text { Tool / Metode / } \\
\text { Hasil }\end{array}$ \\
\hline \multirow[t]{5}{*}{$\begin{array}{l}\text { Komunikasi } \\
\text { dan } \\
\text { perencanaan }\end{array}$} & $\begin{array}{l}\text { Studi Literatur } \\
\text { (Buku, Jurnal) }\end{array}$ & $\begin{array}{c}\text { Studi Lapangan } \\
\text { (Wawancara, Observasi) }\end{array}$ & \multirow{5}{*}{\begin{tabular}{|l} 
Studi lapangan \\
$-\quad$ Wawancara \\
$-\quad$ Observasi \\
Studi literatur \\
$-\quad$ UML \\
$-\quad$ GIS \\
Hasil : \\
$\quad$ Proposal
\end{tabular}} \\
\hline & \multicolumn{2}{|c|}{$\downarrow$} & \\
\hline & \multirow{2}{*}{\multicolumn{2}{|c|}{$\begin{array}{c}\text { Mengidentifikasi Masalah } \\
\text { Menemukan Tujuan Penelitian } \\
\text { Menemukan metodologi Penelitian }\end{array}$}} & \\
\hline & & & \\
\hline & \multicolumn{2}{|c|}{$\downarrow$} & \\
\hline \multirow{6}{*}{$\begin{array}{l}\text { Analisa dan } \\
\text { Perancangan }\end{array}$} & \multirow{2}{*}{\multicolumn{2}{|c|}{ Analisa }} & \multirow{5}{*}{$\begin{array}{l}\text { Tool : } \\
\text { UML } \\
\begin{array}{ll} & \text { Use Case } \\
& \text { diagram } \\
-\quad \text { Skenario }\end{array}\end{array}$} \\
\hline & & & \\
\hline & \multirow{2}{*}{\multicolumn{2}{|c|}{$\begin{array}{l}\text { - Analisa Masalah } \\
\text { - Analisa Sistem } \\
\text { - Analisa Sistem yang sedang berjalan } \\
\text { - Permasalahsn sistem yang sedang berjalan dan } \\
\quad \text { wsulan nerhaikan }\end{array}$}} & \\
\hline & & & \\
\hline & \multicolumn{2}{|c|}{ Perancangan Sistem } & \\
\hline & \multicolumn{2}{|c|}{$\begin{array}{l}\text { Menggambarkan proses dengan diagram activity } \\
\text { Menggambarkan hubungan antar class dalam } \\
\text { sequence diagram } \\
\text { Menggambarkan antar muka }\end{array}$} & $\begin{array}{l}\text { Hasil : } \\
\text { Sebuah aplikasi } \\
\text { pasar berbasis } W e b\end{array}$ \\
\hline
\end{tabular}




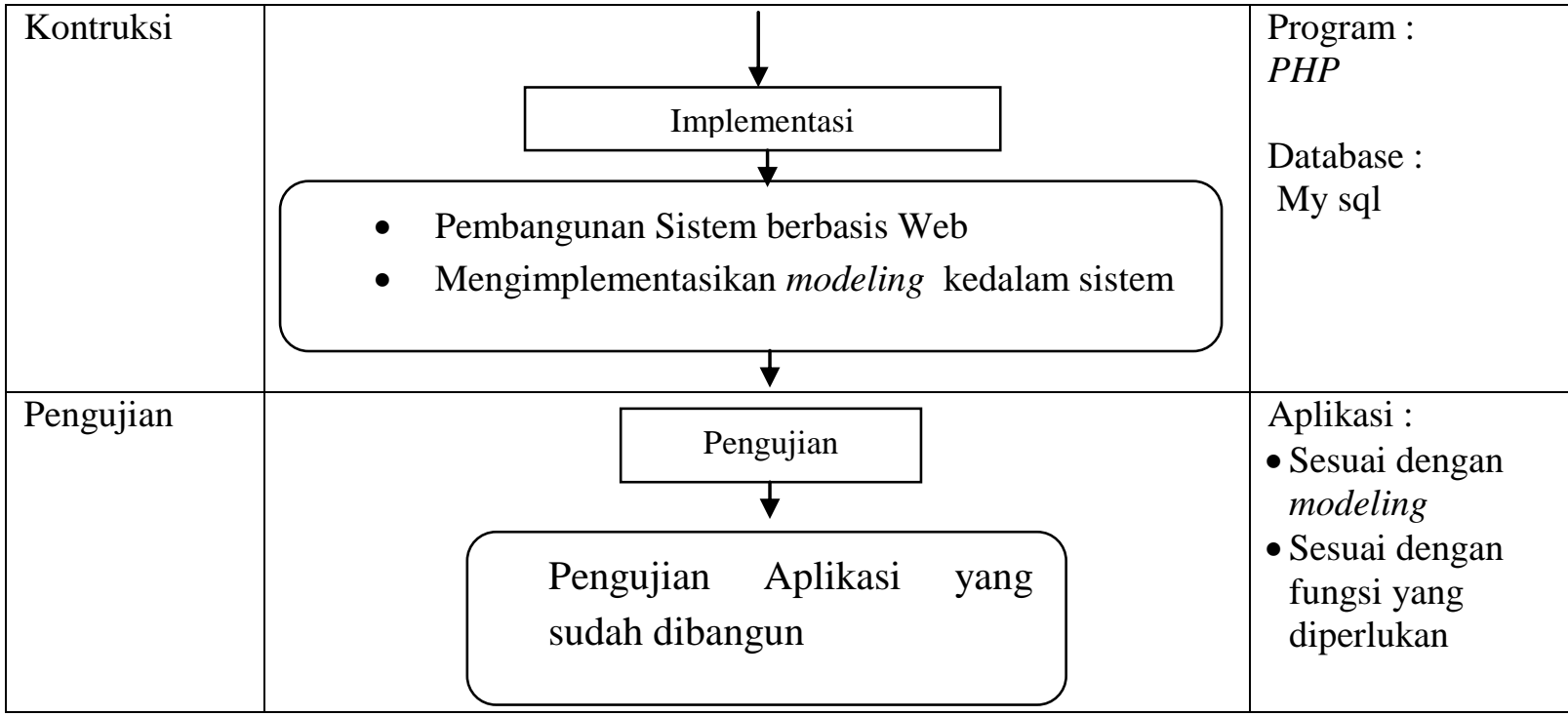

\section{Gambar 1. kerangka kerja penelitian}

a. Use Case Diagram Sistem yang di Usulkan

Use case diagram dibawah ini menggambarkan proses-proses pada sistem informasi geografis pasar tradisional yang akan dibuat, dimana admin memiliki akses penuh dalam aplikasi web, sementar user / konsumen / masyarakat hanya memiliki akses membuka web untuk melihat informasi tentang pasar meliputi profil, nama pasar dan alamat pasar.

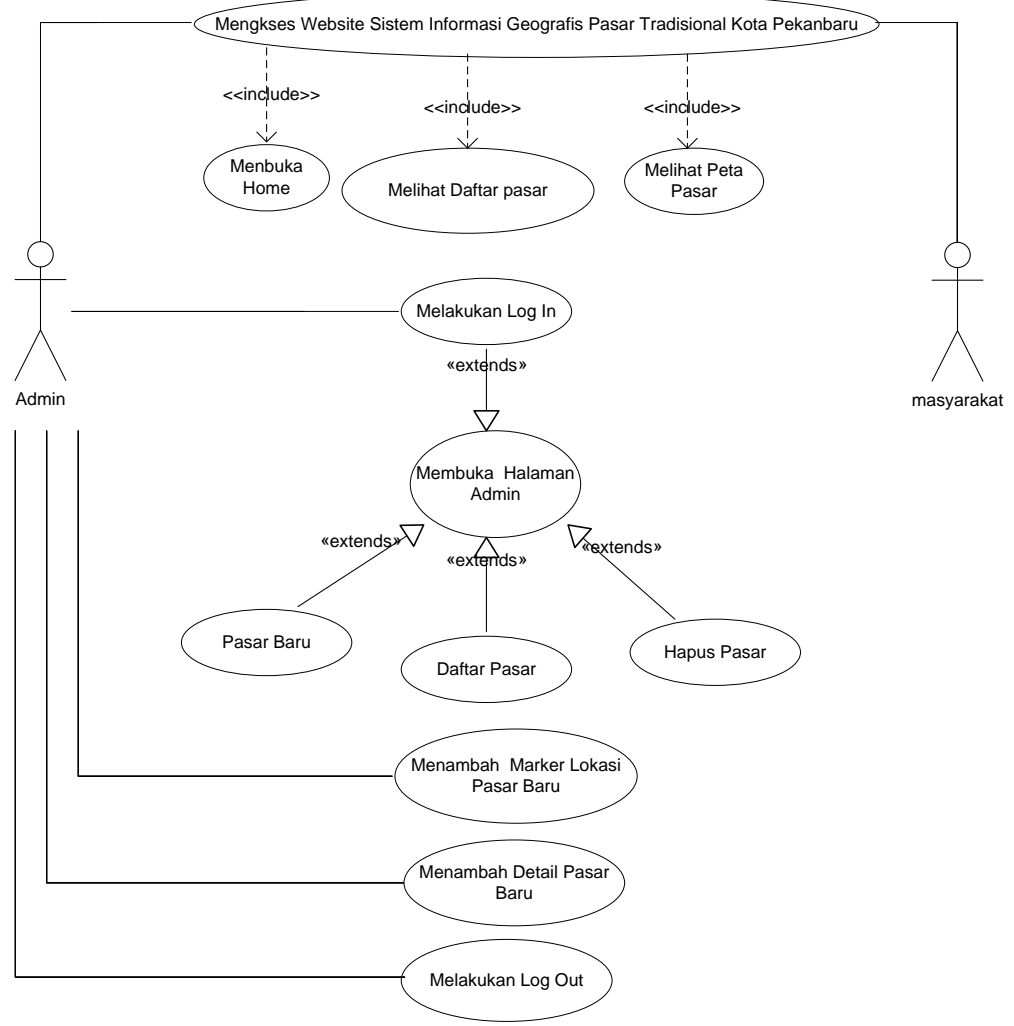

Gambar 2 Usecase Diagram 


\section{b. Activity Diagram Peta}

Pada activity diagram peta dibawah ini menggambarkan aktivitas yang dilakukan admin dalam pengolahan sistem, dimana admin dapat melakukan penambahan, perubahan serta penghapusan data tentang peta pasar yang ada di Kota Pekanbaru.

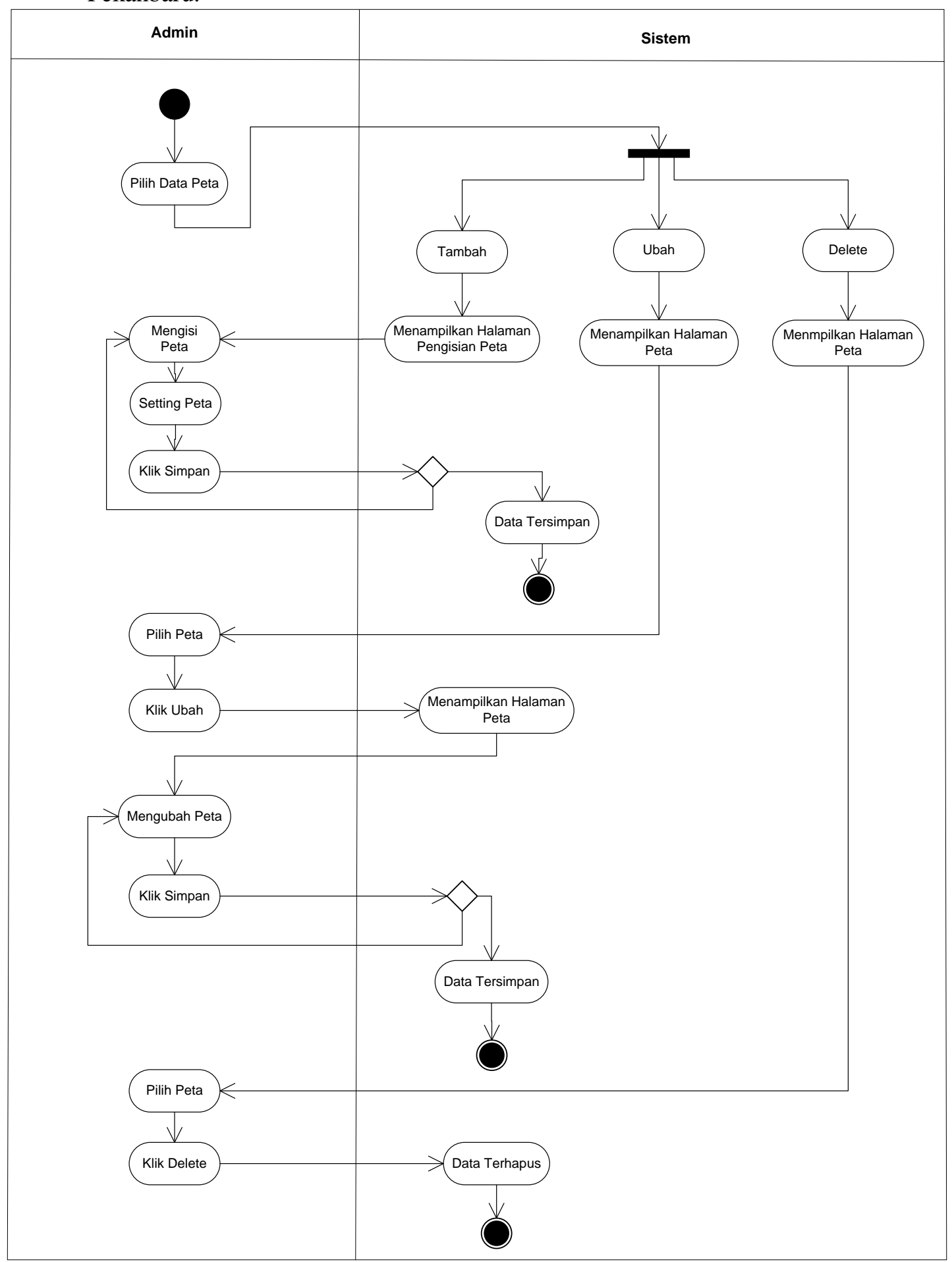

Gambar 3 Activity Diagram Peta 
c. Activity Diagram Pasar

Pada activity diagram peta dibawah ini menggambarkan aktivitas yang dilakukan admin dalam pengolahan sistem, dimana admin dapat melakukan penambahan, perubahan serta penghapusan data tentang pasar yang ada di Kota Pekanbaru.

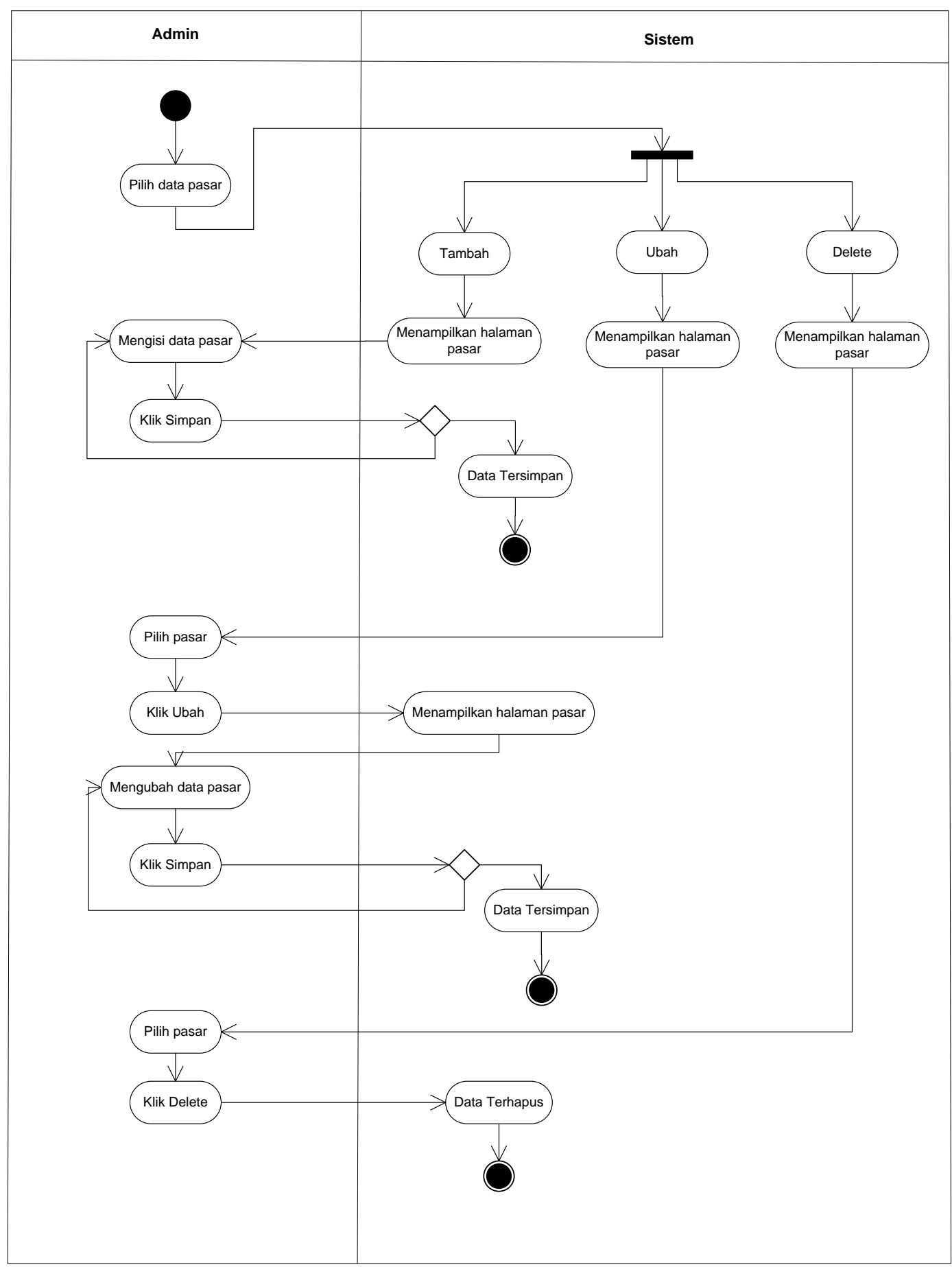

Gambar 4. Activity Diagram Pasar 


\section{d. Sequence Diagram}

Pada tahap ini penulis akan menjelaskan Sequence Diagram agar dapat mempermudah melihat interaksi antar aktor, Sistem dan database secara dinamis.

\section{Diagram Sequence Login}

Agar dapat mengakses sistem informasi geografis dengan otoritas masing-masing aktor, maka aktor harus melakukan login dengan mengisikan username dan password di halaman web.

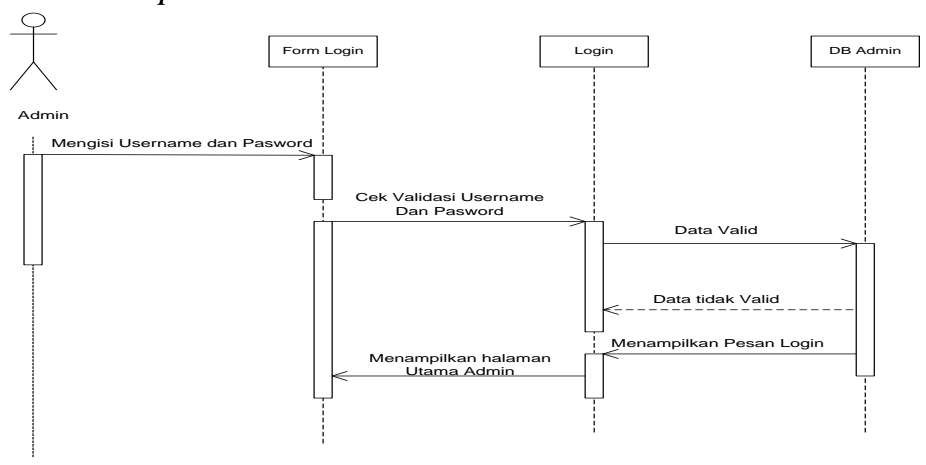

Gambar 5. Diagram Sequence Login

\section{Diagram Sequence Input Data Pasar}

Setelah admin berhasil melakukan login, maka admin dapat langsung mengimput data pasar guna menambahkan informasi tentang pasar yang meliputi, Fasilitas, lokasi, jumlah pedagang, luas pasar.

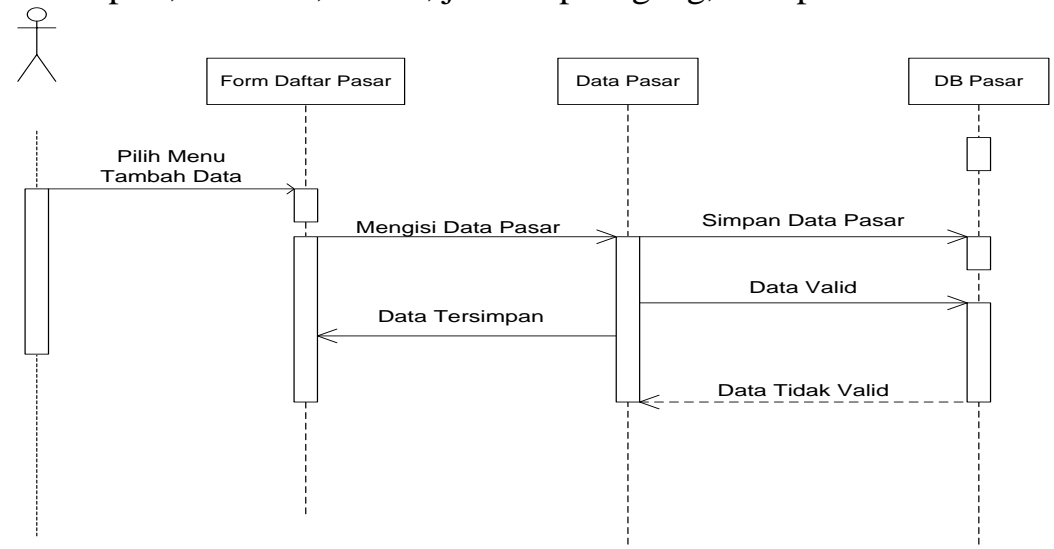

\section{Gambar 6. Diagram Sequence Input Data Pasar}

\section{Diagram Sequence Ubah Data Pasar}

Setelah admin berhasil melakukan login, maka admin dapat langsung mengubah data pasar guna merubah informasi tentang pasar jika ada perubahan data yang meliputi, fasilitas, lokasi, jumlah pedagang, luas pasar. 


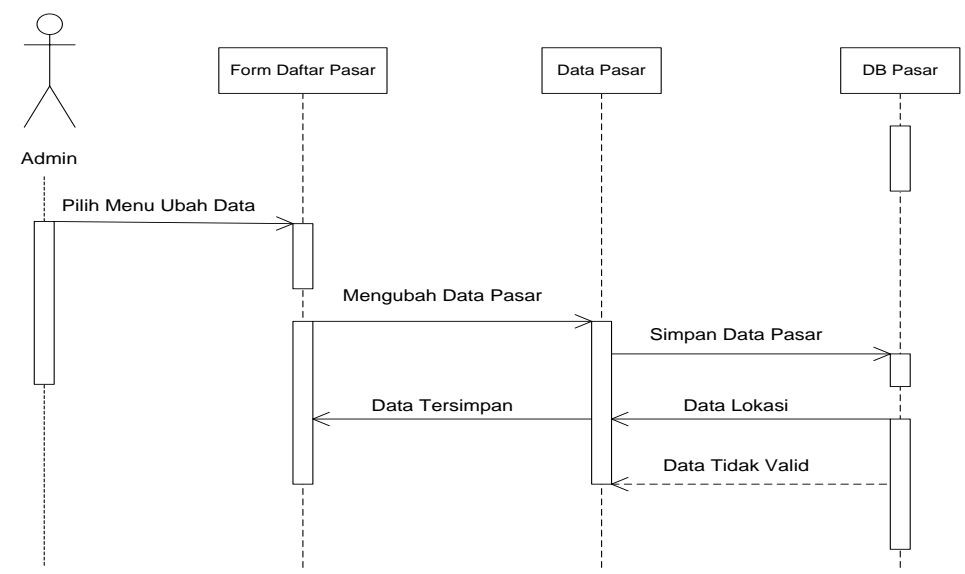

Gambar 7. Diagram Sequence Ubah Data Pasar

\section{Diagram Sequence Hapus Data Pasar}

Setelah admin berhasil melakukan login, maka admin dapat langsung menghapus data pasar guna menghapus informasi tentang pasar jika pasar tersebut tidak beroperasi / digunakan lagi di kota Pekanbaru.

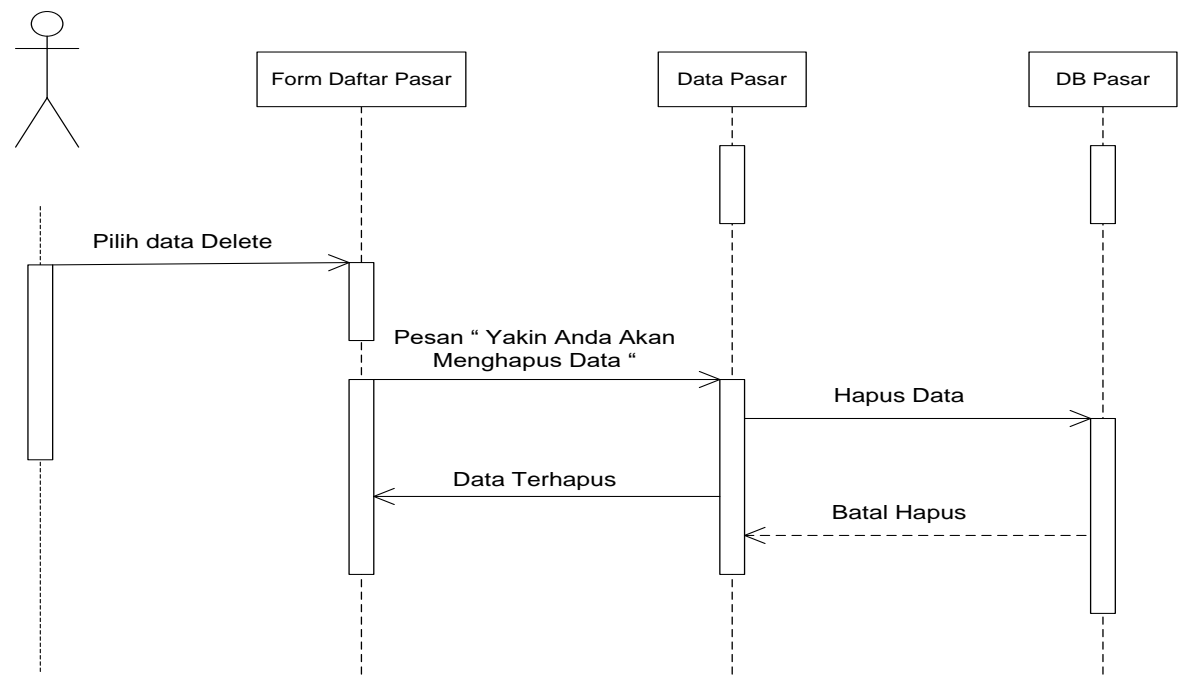

Gambar 8. Diagram Sequence Hapus Data Pasar

\section{e. Statechart Diagram}

Pada bagian ini menggambarkan transisi dan perubahan keadaan (dari satu state ke state lainnya) suatu objek pada sistem sebagai akibat dari stimuli yang diterima, baik yang dilakukan oleh user/pengguna maupun admin sebagai pengelolah sistem. 


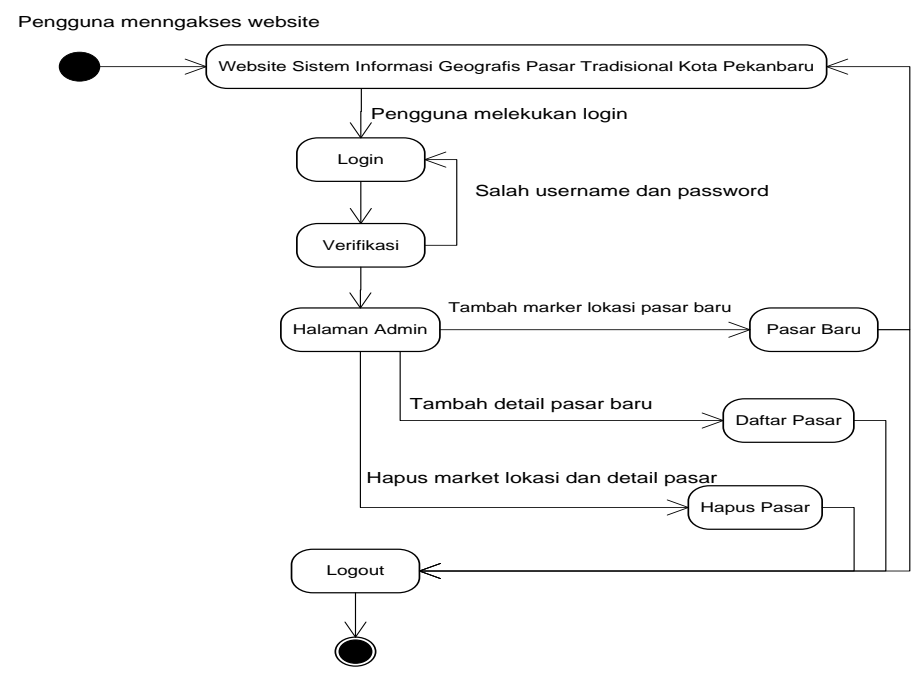

\section{Gambar 9. Statechart Diagram Sistem Usulan Sistem Informasi Geografis Pasar}

\section{f. Daftar Kandidat Kelas}

Berikut merupakan daftar kandidat kelas yang akan menjadi kelas-kelas yang ada pada class diagram yang didapat dari diagram sequence yang sudah dibuat sebelumnya.

\section{Tabel 4.11 Daftar Kandidat Kelas}

\begin{tabular}{|l|l|l|l|l|}
\hline No & \multicolumn{1}{|c|}{ Usecase } & \multicolumn{1}{|c|}{ Interface/Form } & \multicolumn{1}{c|}{ Class Control } & \multicolumn{1}{c|}{ Tabel } \\
\hline 1 & Login & Form Login & Control Login & Tb_admin \\
\hline 2 & Daftar Pasar & Form Daftar Pasar & Control data pasar & Tb_pasar \\
\hline 3 & Peta & Form Peta Pasar & Control data peta & Tb_lokasi \\
\hline
\end{tabular}

\section{g. Class Diagram}

Berikut merupakan class diagram yang telah disusun berdasarkan daftar kandidat kelas yang telah dibahas sebelumnya.

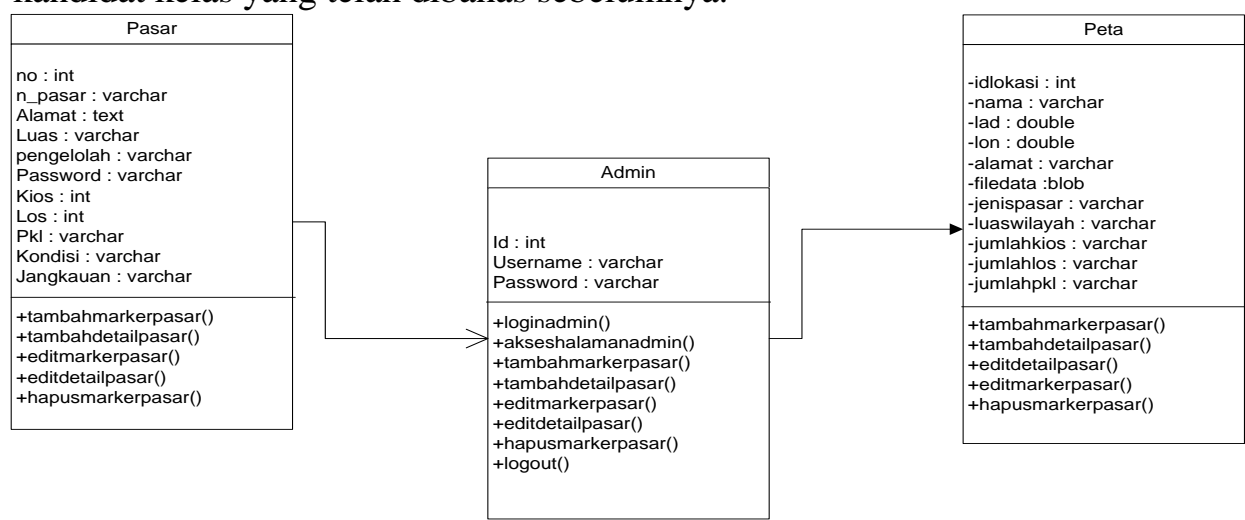

Gambar 10. Class Diagram

\section{Hasil dan Pembahasan}

\subsection{Implementasi Sistem}

Setelah desain sistem selesai, maka tahap selanjutnya adalah implementasi atau pengujian sistem yang telah dibuat. Pada tahap ini dilakukan langkah-langkah pengoperasian sistem GIS pasar tradisional. 
a. Halaman Login Admin

Tampilan halaman login disediakan hanya untuk admin, karna seluruh data pada sistem informasi geografis ini dikelola oleh admin. Tampilan halaman login dapat dilihat pada gambar 11 dibawah ini:

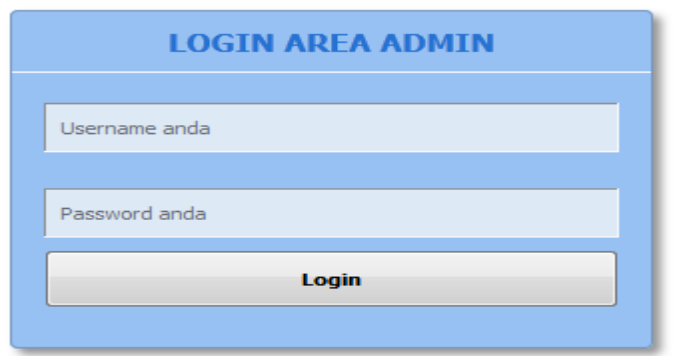

\section{Gambar 11. Tampilan Halaman Login Admin}

b. Halaman Peta Pasar Admin

Pada halaman ini admin dapat mengubah dan menghapus data peta pasar, ini bisa dilihat pada dibawah ini:

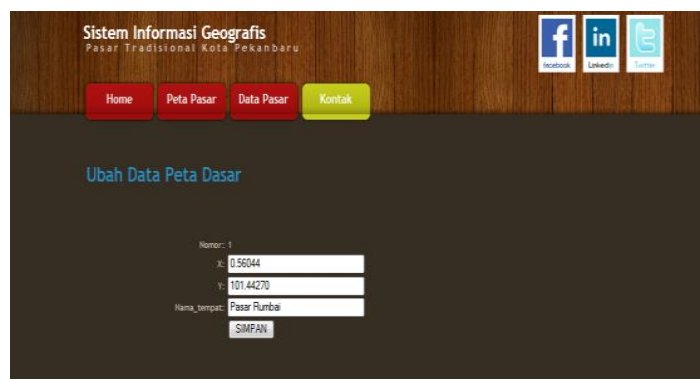

\section{Gambar 12. Tampilan Halaman Ubah Data Peta Pasar}

c. Halaman Tambah Data Peta Pasar

Halaman ini disediakan agar admin dapat menambahkan data peta pasar. Ini dapat dilihat pada gambar 13 dibawah ini:

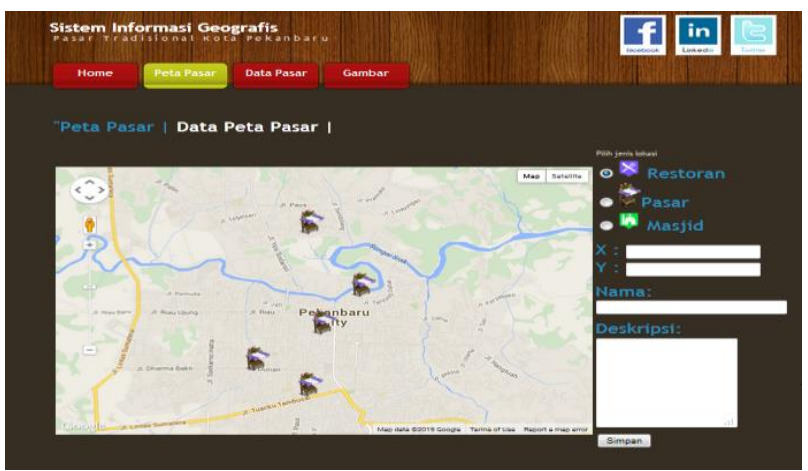

Gambar 13. Tampilan Halaman Tambah Data Peta Pasar 


\section{Kesimpulan}

Dari hasil pengumpulan data sampai pengujian, didapatkan hasil kesimpulan yaitu :

1. Metode UML sangat membantu dalam proses perancangan sebuah sistem informasi geografis pasar tradisonal kota Pekanbaru.

2. Aplikasi sistem informasi geografis pasar tradisional berbasis web ini dapat digunakan sebagai sarana informasi pasar, khususnya bagi para calon pedagang yang ingin berdagang di salah satu pasar tradisional yang ada di Kota Pekanbaru.

3. Aplikasi sistem informasi geografis Pasar tradisional yang di bangun ini sebagai pengembangan dan pembuatan media promosi pasar tradisional yang mulai terancam keberadaanya oleh pasar modren.

Saran untuk pengembangan kedepan nya:

1. Aplikasi sistem informasi geografis pasar tradisional kedepannya dapat mengetahui alat transportasi yang bisa digunakan dari suatu pasar ke pasar lainya, beserta biaya atau ongkosnya dari masing-masing alat transportasi.

2. Aplikasi sistem informasi geografis pasar tradisional kedepanya bisa mempunyai fitur cari pasar terdekat dengan memanfaatkan teknologi GPS.

\section{Daftar pustaka}

[1] Slamet Winardi, Muchamad Aminullah, Pemodelan dan Simulasi Keberangkatan dan Kedatangan Kereta Api Serta Perjalanan Antar Stasiun. NEUTRON 2011, Vol.11, No.2 :37-47.

[2] Haviluddin, Memahami Penggunaan UML (Unified Modelling Language).Jurnal Informatika Mulawarman, 2011, Vol.6, No.1.

[3] Adi Nugroho, Rekayasa Perangkat Lunak Berorientasi Objek dengan Metode USDP (Unified Software Development Process). Penerbit ANDI : Yogyakarta. 2010.

[4] Murianto, Arya Yugi B. Pemanfaatan Sistem Informasi Geografis Berbasis Web Untuk Pemetaan Lokasi Pasar dan Pusat Perbelanjaan di Kota Solo. Spektrum Industri, 2012, Vol.10, No.1 : 1-107.

[5] Weda Kupita, Rahadi Wasi bintoro. Implementasi Kebijakan Zonasi Pasar Tradisional dan Pasar Modern (Studi di Kabupaten Purbalingga). Jurnal Dinamika Hukum,2012, Vol.12 No.1 : 45-59.

[6] Rahman Hardianto, Yuni Nuraini, S.T, Perangkat lunak Informasi Wisata di Bandung dan Sekitarnya Berbasis Android. JURNAL LPKIA, 2014, Vol.1, No.1 : 1-107.

[7] Luh Putu Ayu Prapitasari, Ni Kadek Sumiari, Ni Ketut Dewi Ari Jayanti, Sistem Informasi Geografis Pasar Tradisional di Wilayah Denpasar menggunakan Framework YII . Jurnal Ilmiah SISFOTENIKA, 2016, Vol. 6, No. 2 : 205-216. 